\title{
Phytochemical Analysis, Antioxidant and Antibacterial Activity Determination of Ethanolic Extract of Carica Papaya Seeds
}

\author{
Carlina Kong Jia Ying, Nabila Perveen, Neeraj Paliwal and Naeem Hasan Khan* \\ Faculty of Pharmacy, AIMST University, Malaysia
}

*Corresponding author: Naeem Hasan Khan, Faculty of Pharmacy, AIMST University, 08100 Bedong, Kedah D.A., Malaysia

\begin{tabular}{|c|c|}
\hline ARTICLE INFO & \multirow{5}{*}{$\begin{array}{l}\text { ABSTRACT } \\
\text { In the present study, the Carica Papaya Seeds (CPS) were extracted by using 95\% } \\
\text { ethanol with Soxhlet extraction method. After the plant extract was subjected for the } \\
\text { sterility test and results showed no growth of bacteria, the plant extract was examined } \\
\text { for the phytochemical screening. The antibacterial test was carried out with agar well } \\
\text { diffusion via examination of nutrient and tryptic soy agar. MIC test is used to determine } \\
\text { whether the bacteria can be inhibited by plant extract concentrations that are achievable } \\
\text { and safe in the blood stream, it was conducted by culturing microorganism in liquid } \\
\text { media. The antioxidant activity and total phenolic content were carried out to identify } \\
\text { the IC50 value and the total amount of phenolic content of CPS. For the phytochemical } \\
\text { screening test, the results showed the presence of alkaloids, anthraquinone, flavonoids, } \\
\text { and carbohydrate. The DPPH radical scavenging assay and total phenolic test were shown } \\
\text { positive for the antioxidant activity of the CPS. As a basis, Folin-Ciocalteu reagent was } \\
\text { used to measure the phenolic content of different concentrations of plant extract. In this } \\
\text { test, the Gallic acid was used as a standard and the total phenolic content was calculated } \\
\text { by using the formula C = (A/B) x dilution factor. In the present study, the total phenolic } \\
\text { content found was } 6.420 \text { mg GAE/g and } 6.097 \text { mg GAE/g for the concentrations of } 50 \text { and } \\
200 \mu \mathrm{m} / \mathrm{ml} \text { respectively. According to the results obtained, the IC50 was calculated for the } \\
\text { BHT as well as CPS extract, the value was } 84.04 \mu \mathrm{g} / \mathrm{ml} \text { and } 182.82 \mu \mathrm{g} / \mathrm{ml} \text {, respectively. } \\
\text { Besides that, the percentage scavenging value obtained for the ethanolic } C \text {. papaya seed } \\
\text { was inconsistentand notprecise, therefore the results cannot be considered or equivalent } \\
\text { to the antioxidant activity exerted by the CPS as the results are not reliable. However, it } \\
\text { can be concluded that the CPS are exhibiting antioxidant effect as it shows positive results } \\
\text { for the Total Phenolic Content (TPC) as well as DPPH scavenging method. }\end{array}$} \\
\hline Received: 些 February 02, 2021 & \\
\hline Published: February 10, 2021 & \\
\hline $\begin{array}{l}\text { itation: Carlina Kong Jia Ying, Nabila } \\
\text { erveen, Neeraj Paliwal, Naeem Hasan } \\
\text { han. Phytochemical Analysis, Antioxidant } \\
\text { nd Antibacterial Activity Determination } \\
\text { f Ethanolic Extract of Carica Papaya } \\
\text { eeds. Biomed J Sci \& Tech Res 33(5)- } \\
\text { 021. BJSTR. MS.ID.005459. }\end{array}$ & \\
\hline $\begin{array}{l}\text { Keywords: Antibacterial; antioxidant; } \\
\text { phytochemical; Carica papaya seeds; } \\
\text { Soxhlet }\end{array}$ & \\
\hline
\end{tabular}

\section{Introduction}

Plants, the greatest invention of Almighty God are the 'lungs' of our lovely planet. Plants are just like the 'treasure box' hidden with a lot of active components that are essential for the process of developing new medicine. Medicinal plants not only considered as a readily available and affordable source, but they are also able to synthesize diverse active compounds which are effective in controlling and treating many diseases. These active compounds are known as secondary metabolites, such as phenols, tannins, alkaloids, flavonoids, glycosides, saponins and carbohydrates. Medical uses of plants range from extraction and decoction of leaf, bark, root, flower, seeds and stem portion of the plant. Carica papaya (CP) is one of the medicinal plants that contributed as a remedy against a variety of diseases. Papaya, papaw or pawpaw belongs to the Caricaceae family and is scientifically known as Carica papaya. Carica papaya is a tropical fruit which is one of the major fruit crops cultivated in tropical and sub-tropical zones due to its tasty and juicy flesh, other than that, the increment in demand is because of the high medicinal and nutritive value possessed by papaya fruit [1]. The CP is believed to be native to southern Mexico and neighbouring Central America. The medicinal uses of CP are listed in Table 1. 
Table 1: Medicinal uses of C. papaya plant mentioned in traditional Ayurvedic literature.

\begin{tabular}{|c|c|}
\hline Parts & Medicinal uses \\
\hline \multirow{2}{*}{ Ripe fruits } & Carminative, diuretic, \\
\cline { 2 - 2 } Unripe fruits & chronic diarrhea, dysentery, ringworm \\
\cline { 2 - 2 } Seeds & Diuretic, antibacterial \\
\hline \multirow{2}{*}{ activity, laxative, abortifacient } \\
\cline { 2 - 2 } & $\begin{array}{c}\text { Carminative, counter irritant, as a paste in the } \\
\text { treatment of ringworm and }\end{array}$ \\
\hline \multirow{2}{*}{ Roots } & psoriasis \\
\cline { 2 - 2 } Leaves & Anti-fungal activity, \\
\cline { 2 - 2 } & diuretic, piles \\
\hline \multirow{2}{*}{ Flower } & Asthma, beriberi, fever, abortion, antibacterial \\
\cline { 2 - 2 } & activity, gonorrhea \\
\hline \multirow{2}{*}{ Stem bark } & Febrifuge, jaundice, pectoral \\
\cline { 2 - 2 } & properties \\
\hline
\end{tabular}

Recently, the CPS has been studied further for its uses and identified the presence of any medicinal values and nutrients. Unlike the 'old-fashioned' way it is dealt with the papaya seeds, nowadays, the seeds are used for many purposes, for example the seeds are processed and grounded to substitute black pepper. Even though the papaya seeds are unpalatable due to its peppery and spicy taste, it is however, having potent activity compared to the flesh of CP [2]. Other than consumption purposes, the papaya seeds can be used as an antibacterial agent as it is effective against many microorganisms, such as E. coli, S. typhi and S. aureus. Some studies showed significant anti-helminthic and anti-amoebic properties. The Taxonomical classification of $\mathrm{CP}$ is shown in Table 2 and the different medicinally important parts of the plant are shown in Figure 1.

Table 2: Taxonomical classification of Carica papaya.

\begin{tabular}{|c|c|}
\hline Rank & Scientific Name and Common Name \\
\hline Kingdom & Plantae - Plants \\
\hline Subkingdom & Tracheobionta - Vascular plants \\
\hline Superdivision & Spermatophyta - Seed plants \\
\hline Division & Magnoliophyta - Flowering pants \\
\hline Class & Magnoliopsida - Dicotyledons \\
\hline Subclass & Dilleniidae \\
\hline Order & Violales \\
\hline Family & Caricaceae - Papaya family \\
\hline Genus & Carica L. - papaya \\
\hline Species & Carica papaya L. - papaya \\
\hline
\end{tabular}

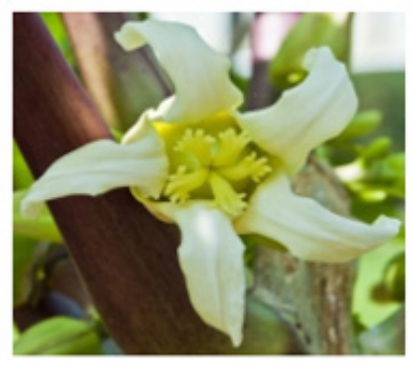

(A)

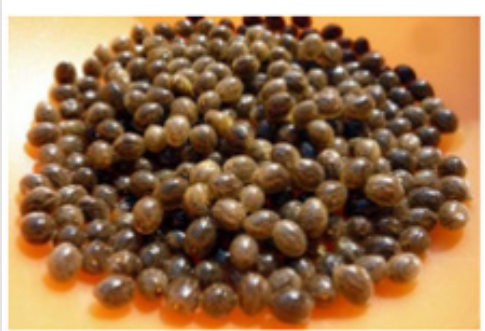

(D)

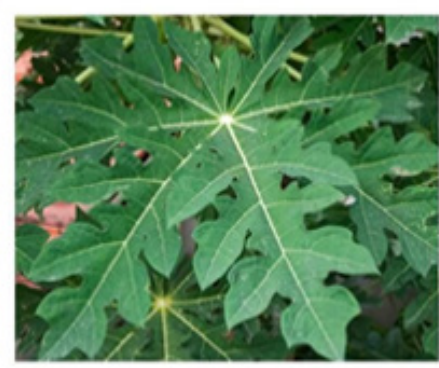

(B)

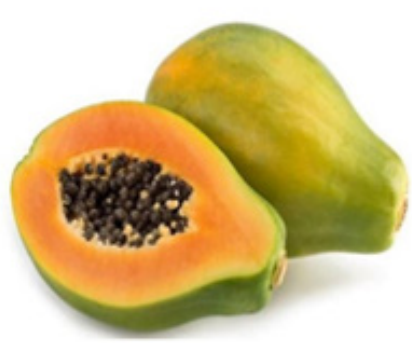

(C)

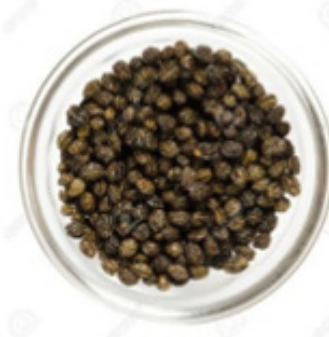

(E)

Figure 1: Carica papaya:

(A) Papaya flower

(B) Papaya leaf

(C) Ripe fruits

(D) Papaya seed

(E) Dried see 


\section{Sample Preparation / Extraction Process}

Generally, sun drying is the most acquired method to dry the plant sample because it is cost- saving. A minimum temperature of $30{ }^{\circ} \mathrm{C}$ or higher is required and several days will be taken to eliminate the excessive moisture content of the sample [3]. After the drying process, the dried plant sample must be preserved in a dry container with low humidity conditions to prevent the absorption of the moisture by the dried sample. Next, the dried sample is needed to reduce in size as the bigger surface area can enhance the contact point between the sample and the solvent utilised, thus facilitate the extraction process. The dried sample can be ground into either powder or pieces form by using a grinding machine or mortar and pestle. Next, the extraction process can be started by placing the dried sample and solvent together in a vessel or extraction instrument. The extraction of CPS were carried out with ethanolic Soxhlet extraction, the evaporation and total dryness over hot water bath.

Phytochemical Screening Unlike pharmaceutical chemicals, phytochemicals are safe and dependable, compared to costly synthetic drugs which are invariably associated with adverse effects, therefore it is considered as "man-friendly medicine". Some phytochemicals are known to possess medicinal and physiological activities which are alkaloids, saponins, flavonoids, tannins, glycosides anthraquinones and terpenoids [4]. 2\% of CPS extract was prepared by dissolving $1.0 \mathrm{~g}$ of extract in $50 \mathrm{ml}$ of distilled water to form a solution which was used for phytochemical screening. Various tests, mainly chemical reaction identification by colour change or precipitate formations, were used to determine the presence of phytochemical constituents: saponins (Foam), alkaloids (Mayer and Wagner), Tannin (Ferric Chloride), Anthraquinone (Hydrochloric Acid, Chloroform, Ammonia). Glycosides (Hydrochloric Acid, Sodium Hydroxide, Fehling A and B), Reducing sugar (Barfoed, Molisch, Fehling), Flavonoids (Lead Acetate), Terpenoids (Salkowski, Liebermann Burchard).

\section{Antioxidant Assay}

An antioxidant is a bioactive compound that scavenges the free radicals from body cells and prevents or reduces the damage caused by Reactive Oxygen Species (ROS). ROS is produced during mitochondrial oxidative metabolism as well as in cellular response to xenobiotics, cytokines and bacterial invasion. DPPH is known as a stable free radical by the delocalisation of the spare electron over the molecule as a whole, so that the molecules do not dimerise, like most other free radicals. Besides that, the delocalisation had resulted in deep violet colour, with absorption in ethanol solution at around $520 \mathrm{~nm}$. Upon the mixture of DPPH solution with the sample extract that can donate a hydrogen atom, the permanent deep violet colour will be decolourised and become yellow colour. DPPH appears to have stronger absorption at the band of $517 \mathrm{~nm}$ due to its odd electron and gives rise to a deep violet color solution. According to the number of electrons captured, the solution will be decolorized stoichiometrically [5]. The extraction of antioxidant compounds of the sample can be facilitated by carrying out the reaction of the sample with DPPH in methanol. The DPPH method comes with a lot of advantages, for instance it is allowed to react with the whole sample also, DPPH is able to react with weak antioxidants slowly if sufficient time is provided. Furthermore, DPPH method may be utilized in aqueous and nonpolar organic solvents and can be used to examine both hydrophilic and lipophilic antioxidants [6].

\section{Antibacterial Assay}

According to the report shown, the skin, pulp and seeds of Carica papaya contain numerous types of phytochemicals which may be one of the sources to synthesize antimicrobial drugs. This is one of the aims of this study which is to identify the antibacterial potential of ethanolic CPS [7]. The antimicrobial assay was carried out by using gram-positive and gram- negative bacteria, such as Streptococcus pneumoniae ( $S$. pneumoniae), Staphylococcus aureus (S. aureus), Salmonella typhi (S. typhi), Escherichia coli (E. coli), Pseudomonas aeruginosa (P. aeruginosa), Bacillus subtilis (B. subtilis), Micrococcus luteus (M. luteus) and many more. Before conducting the antimicrobial test, it is essential to determine which media is suitable for that particular bacteria followed by the cultivation of the bacteria. The two main types of bacterial growth media are broth and agar [8]. For some bacteria such as $S$. aureus, E. coli and S. typhi, they are suitable to be cultured in the nutrient agar and nutrient broth, whereas for both $P$. aeruginosa and $B$. subtilis, they are usually cultivated in the tryptic soy broth and tryptic soy agar. The broth will be initially sterilized and then inoculated with the bacteria of interest, followed by incubation for 24 hours to encourage bacterial growth. After the incubation step, the broth will be incorporated into the agar in order to carry out the antibacterial assay [9].

Commonly, the method that employed the antibiotic susceptibility test is the agar diffusion method. It involves the application of different concentrations of antibiotics and added into the wells, made with the cork borer, of the agar plates seeded with the bacterial strain [10]. The slow diffusion of the antibiotic into the agarose medium leads to the inhibition of the bacterial growth around the wells, in which there will be the formation of a clear inhibition zone that can be observed clearly. The diameter of the zone of inhibition will increase as the concentration of the antibiotic and the sample increase [11]. As an observation, the diameter of the zone of inhibition will be measured by using calliper and the values will be recorded as results. After the identification of the concentration effective in inhibiting the bacterial growth in the agar diffusion assay, it is then carried on with the minimum inhibitory concentration test. It is important to determine the lowest concentration of an antimicrobial agent that inhibits the growth of microorganisms. As an effective antimicrobial agent, the MIC scores should be lower as it indicates that less concentration is required to prevent the growth of microbes. After 24 hours of incubation, if the mixture of the mi- 
croorganism and antimicrobial agent turns cloudy, this indicates the microorganism had maximum growth and the test agent does not pose antimicrobial activity at that particular dilution [12]. However, the viable microorganism in low-level that remains in the test tube after incubation cannot be differentiated from the microbes that have been killed by the antimicrobial agent. Due to that, MIC assay is not used as an indicator of bactericidal activity. The Minimum Bactericidal Concentration (MBC) is compulsory to the MIC. The MBC of an antibacterial can be determined by sub-culturing the last clear MIC tube onto the growth medium and examining for bacterial growth. The plate that does not show any bacterial growth will be the minimum bactericidal concentration [13]

\section{Methodology}

\section{Chemicals / Equipment}

Nutrient Agar (HiMedia Laboratories Pvt.Ltd. India), Nutrient Broth (HiMedia Laboratories Pvt.Ltd. India), Tryptic Soy Agar (HiMedia Laboratories Pvt.Ltd. India), Tryptic Soy Broth (HiMedia Laboratories Pvt.Ltd. India), Ciprofloxacin, Penicillin,70\% Alcohol, Plant Extract and Dimethyl Sulfoxide (DMSO) (Fisher Scintific UK). Ethanol 95\% (John Kollin Corporation, USA), Methanol (J.T. Baker. Center Valley, PA), $\alpha, \alpha$-diphenyl- $\beta$-picrylhydrazyl (DPPH) (Sisco Research Laboratories Pvt. Ltd, India.), Butyl Hydroxyl Toluene (BHT), Sodium Carbonate (Bendosen Laboratory Chemicals), FolinCiocalteu's Phenol Reagent (EMD M.C. Germany), Gallic Acid (R\&M Chemicals, UK).

Shimadzu UV- Visible Spectrophotometer.

\section{Bacterial Strains}

The cultures were used for the antibacterial assay. These cultures were obtained from microbial culture bank of faculty of pharmacy (FOP), Aimst University.

1. Escherichia coli (E. coli) ATCC 8739.

2. Staphylococcus aureus (S. aureus) ATCC 29737.

3. Bacillus subtilis (B. subtilis) ATCC 6633.

4. Salmonella typhi (S. typhi) ATCC 19430.

\section{Antioxidant Assay}

The CPS were cleanly washed and air-dried at room temperature for 1 week to prevent the seeds from undergoing deterioration [14]. The dried seeds were passed through a sieve $1.40 \mathrm{~mm}$ to remove the unwanted impurities and then pulverized into powder form using the mortar and pestle. Figure $2 a \& 2 b$ indicated fresh and dried seeds respectively. The extraction of the seeds was carried out using ethanol as an extracting solvent. The Soxhlet extraction method was employed to extract the chemical constituents in the $C$. papaya seeds [15]. 19.38 gm of the CPS powder was inserted into a thimble $300 \mathrm{ml}$ of ethanol was measured accurately and added into the round bottom flask. The vapour formed during the extraction process were allowed to condense and accumulate back in the
Soxhlet chamber. The running of tap water has remained until the whole apparatus cools down. The $C$. papaya seed extract contained in the round bottom flask was poured into a cleaned and dried conical flask $(1000 \mathrm{ml})$. The conical flask was covered with cotton wool and aluminium foil to prevent evaporation [16].

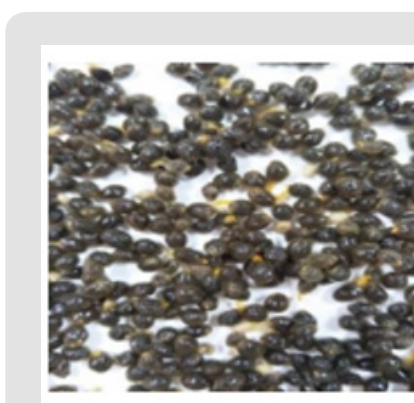

(a)

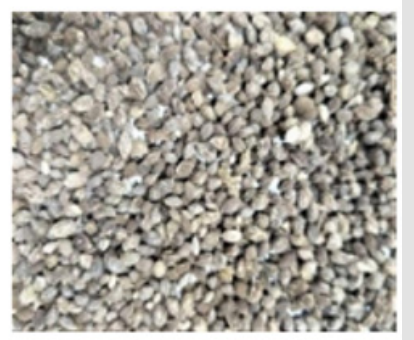

(b)
Figure 2:

(a) Fresh C. papaya seeds

(b) Dried C. papaya seeds

The ethanolic extract of CPS was evaporated by using the rotary evaporator. The temperature of the rotary evaporator was set at $80{ }^{\circ} \mathrm{C}$. The process was continued until no notable changes were observed. The pure CPS extract was poured into a clean beaker. The collected pure extract was introduced into a china dish and placed on the hot water bath for further evaporation [17]. After a few hours, a concentrated extract was formed and the china dish was removed from the hot water bath. The extract was filtered by using the Buchner funnel topped with filter paper. A semi-solid residue of CPS extract was obtained and it was put in the china dish. The china dish was covered with double-folded aluminium foil [18].

\section{Determination of Total Phenolic Content}

Preparation of Standard: Gallic acid was used as a standard in this assay and compared with the sample to identify the presence of phenolic compounds in the plant extract. Five different concentrations of Gallic acid were prepared at 1, 2, 4, 6, 8 and $10 \mu \mathrm{g} / \mathrm{ml}$. The stock solution was prepared by dissolving $10 \mathrm{mg}$ of Gallic acid in $10 \mathrm{ml}$ of $95 \%$ ethanol. Then, $1 \mathrm{ml}$ of the solution was diluted with $9 \mathrm{ml}$ of ethanol to obtain a concentration of $100 \mu \mathrm{g} / \mathrm{ml}$. The same procedure was repeated until the final concentration of $1 \mu \mathrm{g} / \mathrm{ml}$ was obtained. From the stock solution, $1.0,0.8,0.6,0.4,0.2$, $0.1 \mathrm{ml}$ were pipetted into 6 different tubes and labelled accordingly. The volume was then made up to $10 \mathrm{ml}$ with $95 \%$ ethanol. Another 6 clean tubes were prepared [19]. $0.2 \mathrm{ml}$ of the standard solution were taken and transferred into the test tube prepared. $4 \mathrm{ml}$ of $2.5 \%$ sodium carbonate and $0.2 \mathrm{ml}$ of Folin-Ciocalteu reagent was added to each of the test tubes. The test tubes were allowed to sit for 2 hours. The absorbance of the standard solution was examined by 750nm UV spectrophotometry and was recorded [20].

Preparation of Sample: The extracts were obtained from the Soxhlet extraction method using 95\% ethanol. 4 different 
concentrations of the extracts were prepared at 25,50,100,200 $\mu \mathrm{g} /$ $\mathrm{ml} .2 \mathrm{mg}$ of extracts was dissolved in $10 \mathrm{ml}$ of ethanol, forming a stock solution with a concentration of $200 \mu \mathrm{g} / \mathrm{ml}$. Then it was doublediluted by mixing $2 \mathrm{ml}$ of the stock solution and $2 \mathrm{ml}$ of ethanol to obtain the concentration of $100 \mu \mathrm{g} / \mathrm{ml}$. The same procedure was repeated and obtained $50 \mu \mathrm{g} / \mathrm{ml}$ in concentration. Next, $1 \mathrm{ml}$ of stock solution was taken and mixed with $2 \mathrm{ml}$ of ethanol to obtain a concentration of $25 \mu \mathrm{g} / \mathrm{ml} .4$ test tubes were prepared and $0.2 \mathrm{ml}$ of the sample solution were taken and transferred into the test tube prepared. $4 \mathrm{ml}$ of $2.5 \%$ sodium carbonate and $0.2 \mathrm{ml}$ of FolinCiocalteu reagent was added to each of the test tubes [21]. The test tubes were allowed to sit for 2 hours. The absorbance of the standard solution was examined by 750nm UV spectrophotometry and was recorded.

Preparation of Blank: $0.2 \mathrm{ml}$ of Folin-Ciocalteu reagent, $4 \mathrm{ml}$ of $2.5 \%$ sodium carbonate and $0.2 \mathrm{ml}$ of ethanol were added into the test tube and it was allowed to sit for 2 hours. The absorbance of the standard solution was examined by $750 \mathrm{~nm}$ UV spectrophotometry. The values of absorbance of standard and sample obtained were then utilised in plotting the graph of UV absorbance against the concentration of sample and standard [22].

\section{Antioxidant Assay}

\section{DPPH Radical Scavenging Assay (diphenyl-picryl- hydrazyl hydrate)}

Preparation of DPPH Solution: $0.1 \mathrm{mM}$ of methanolic DPPH was freshly prepared by dissolving $3.94 \mathrm{mg}$ of DPPH crystalline powder in $100 \mathrm{ml}$ of methanol and kept in a clean beaker. The beaker was covered with aluminium foil to prevent oxidation.

Preparation of Standard: BHT was used as a standard in this assay. 6 different concentrations of BHT solutions were prepared at $10,20,40,60,80$ and $100 \mu \mathrm{g} / \mathrm{ml}$. The stock solution was first prepared by dissolving $10 \mathrm{mg}$ of BHT in $10 \mathrm{ml}$ of methanol. $1 \mathrm{ml}$ of the solution was then diluted ten-fold with $9 \mathrm{ml}$ of methanol to obtain a concentration of $100 \mu \mathrm{g} / \mathrm{ml}$. From the stock solution, 10, $8,6,4,2,1 \mathrm{ml}$ were pipetted into 6 different test tubes and made up to $10 \mathrm{ml}$ with methanol. Then, $3 \mathrm{ml}$ of $0.1 \mathrm{mM}$ DPPH reagent was added to $2.5 \mathrm{ml}$ of different concentrations of methanolic extracts. The mixtures were shaken and labelled accordingly. The test tubes were allowed to keep in the dark for 30 minutes. The absorbance was measured at $518 \mathrm{~nm}$ using a UV spectrophotometer.

Preparation of Sample: The steps in preparation of DPPH solution were repeated in the preparation of the sample, in which the BHT was changed to the plant extract [23]. The absorbance was measured at $518 \mathrm{~nm}$ using a UV spectrophotometer.

Preparation of Blank : The blank solution was prepared by mixing $3 \mathrm{ml}$ of $0.1 \mathrm{mM}$ DPPH reagent and $2.5 \mathrm{ml}$ of methanol, the solution was allowed to stand in the dark for 30 minutes. The absorbance was measured at $518 \mathrm{~nm}$ using a UV spectrophotometer [24]. The values of absorbance of standard and sample obtained were then utilised in plotting the graph of UV absorbance against concentration of the sample and standard.

\section{Antibacterial Assay}

\section{Sterility test of Ethanolic CPS Extract}

Before the initiation of phytochemical screening, antibacterial and antioxidant assay of $C$. papaya seed extract, the extract was streaked on nutrient agar and was incubated for 24 hours at the temperature of $37{ }^{\circ} \mathrm{C}$. Due to the movement control order in Malaysia, the plant extract was kept in the fridge for about 3 months, therefore the growth promotion test is able to determine whether microbes were present in the plant extract. This enables us to ensure positive results for all tests, especially antibacterial assay. There was no bacterial growth observed after 24 hours of incubation.

\section{Serial Dilution of Plant Extract}

Before the dilution of plant extract, the $0.5 \%$ DMSO was prepared by measured $0.5 \mathrm{ml}$ of DMSO and mixed with $99.5 \mathrm{ml}$ of sterilized distilled water. $400 \mathrm{mg}$ of plant extract was weighed with the use of analytical balance and it was transferred to a clean beaker that contained $40 \mathrm{ml}$ of $0.5 \%$ DMSO. This gave rise to the formation of a stock solution with a concentration of $10 \mathrm{mg} / \mathrm{ml}$. Next, the beaker was subjected to sonication to ensure complete mixing of the two different liquid. From the stock solution, 10, 8, $6,4,2,1 \mathrm{ml}$ were pipetted into 6 different sterilized universal tubes and were labelled accordingly [25]. The volume was then made up to $10 \mathrm{ml}$ with $0.5 \%$ DMSO. The universal tubes were tightly screwed and kept in the refrigerator for storage.

\section{Preparation of Bacteria Strains}

$1.95 \mathrm{~g}$ of nutrient broth powder and $1.5 \mathrm{~g}$ of tryptic soy broth powder were weighed accurately using an analytical balance and transferred into 4 different conical flasks $(100 \mathrm{ml})$. These conical flasks were labelled accordingly. Then, $50 \mathrm{ml}$ of distilled water was measured and poured into each conical flask to dissolve the nutrient broth. After putting magnetic beads into 4 conical flasks, these conical flasks were placed on the magnetic stirrer to facilitate the dissolving process. The mouth of the conical flasks was fitted with cotton wool and covered with double-folded aluminium foil. The 4 conical flasks were sterilized by using an autoclave for 2 hours at the temperature of $121{ }^{\circ} \mathrm{C}$. After sterilization, 4 conical flasks were allowed to cooled down, the universal tubes that contained four different bacterial cultures were incubated in order to revive the microorganisms. Inoculation of the bacteria strains was done in the biosafety cabinet. One loopfull of the bacteria culture of Bacillus subtilis was inoculated into the tryptic soy broth. Steps were repeated with the microorganism Escherichia coli, Staphylococcus aureus and Salmonella typhi, in which these 3 bacteria were inoculated in nutrient broth instead of tryptic soy broth. The 4 conical flasks with bacteria strains were incubated in an incubator at the temperature of $37^{\circ} \mathrm{C}$ for 24 hours. 


\section{Preparation of Nutrient Agar Plate}

$11.2 \mathrm{~g}$ of nutrient agar powder was weighed 3 times and transferred into 3 conical flasks $(1000 \mathrm{ml}) .400 \mathrm{ml}$ of distilled water was measured accurately and poured into each of the flasks. After putting magnetic beads into 3 of the conical flasks, these conical flasks were placed on the magnetic stirrer to facilitate the dissolving process. The mouth of the conical flasks was fitted with cotton wool and covered with double-folded aluminium foil. The conical flasks were subjected to sterilization with the use of autoclave for 2 hours at the temperature of $121{ }^{\circ} \mathrm{C}$. In the biosafety cabinet, the freshly prepared sterilized nutrient agar was poured into the sterilized Petri plates. The inoculation loop was used to eliminate the bubble formed on the surface of the nutrient agar before solidification occurs. Approximately, $25 \mathrm{ml}$ of the nutrient agar was poured into the sterilized Petri plates, these plates were allowed to cool down and solidified in the biosafety cabinet. These plates were incubated in an upside-down position at the temperature of $37{ }^{\circ} \mathrm{C}$ and were taken out during the agar well diffusion test.

\section{Preparation of Tryptic Soy Agar Plate}

(Tryptic soy broth or Trypticase soy broth (frequently abbreviated as TSB) is used as a culture broth to grow aerobic bacteria. It is a complex, general purpose medium that is routinely used to grow certain pathogenic bacteria, which tend to have high nutritional requirements (i.e., they are fastidious). Its agar counterpart is tryptic soy agar (TSA). One of the components of Tryptic soy broth is Phytone which is an enzymatic digest of soybean meal). TSB is frequently used in commercial diagnostics in conjunction with the additive sodium thioglycolate which promotes growth of anaerobes. Tryptic Soy Agar was only applied for the Bacillus subtilis out of the 4 chosen bacterial strain. $20 \mathrm{~g}$ of tryptic soy agar powder was weighed by using an analytical balance and transferred into a $1000 \mathrm{ml}$ conical flask. $500 \mathrm{ml}$ of distilled water was poured into the conical flask and labelled accordingly. After putting the magnetic bead into the conical flask, the conical flask was placed on the magnetic stirrer to facilitate the dissolving process. The mouth of the conical flask was fitted with cotton wool and covered with double-folded aluminium foil. The conical flask was subjected to sterilization with the use of autoclave for 2 hours at the temperature of $121{ }^{\circ} \mathrm{C}$. In the biosafety cabinet, the freshly prepared sterilized tryptic soy agar was poured into the sterilized Petri plates. The inoculation loop was used to eliminate the bubble formed on the surface of the tryptic soy agar before solidification occurs. Approximately, $25 \mathrm{ml}$ of the tryptic soy agar was poured into the sterilized Petri plates, these plates were allowed to cool down and solidified in the biosafety cabinet. These plates were incubated in an upside-down position at the temperature of $37{ }^{\circ} \mathrm{C}$ and were taken out during the agar well diffusion test.

\section{Agar Well Diffusion}

Before the initiation of the agar well diffusion test, the biosafety cabinet was sterilized with $70 \%$ alcohol and the UV light was switched on for 10 minutes. Apart from that, the plant extract dilutions, antibiotic dilutions with the concentration of $5 \mathrm{mg} / \mathrm{ml}$ (Penicillin and Ciprofloxacin), bacteria strains, bacteriological loop, sterilized cork borer, sterilized micropipette tips and micropipette (p100), Bunsen burner and nutrient agar plate were prepared in prior of the test. After switched off the UV light and placement of all materials in the biosafety cabinet, gloves were worn and $70 \%$ alcohol was applied properly to sanitize the gloves to prevent contamination occurs. NA/TSA (nutrient agar/tryptic soy agar), date, name, bacterial strain, ATCC code and antibiotics were labelled accordingly at the bottom side of the plates. $0.1 \mathrm{ml}$ of broth that contained bacterial strain was pipetted into the Petri plates with the use of a micropipette. The sterilized glass spreader was used to spread the bacterial strains evenly on the plate. After every spreading, the glass spreader should be sanitized with $70 \%$ alcohol and showed to the flame. Then the sterilized cork borer was used to make wells on the agar plate. There were 4 wells punched in one Petri plate, each well was separated from each other in equal distance. The plates were prepared in a triplicate manner for the comparison purpose, as well as the positive and negative plates. The cork borer was sterilized every time after use. The agar which was fitted inside the cork borer after punching the wells was discarded. The different concentrations of plant extract as well as different antibiotics were added into the wells by using a micropipette. The wells were filled until $60 \%$ of the height of the wells. The micropipette tips were discarded after each concentration of plant extract and antibiotics was performed. This can prevent an alteration of the concentration of plant extract and antibiotics. The Petri plates were then incubated in an incubator at the temperature of $37^{\circ} \mathrm{C}$ for 24 hours. The zone of inhibition of the plates was observed and recorded.

\section{Minimum Inhibitory Concentration (MIC)}

5 loops of the bacterial strains were cultured in each sterile nutrient broth and then incubated at $37^{\circ} \mathrm{C}$ for 24 hours. Afterward centrifuged at $5000 \mathrm{rpm}$ for 10 minutes.

Preparation of Standard McFarland Bacterial Culture: The nutrient broth as well as tryptic soy broth were prepared freshly. These broths were sterilized for 2 hours at the temperature of $121^{\circ} \mathrm{C}$ and were allowed to cool down. In the biosafety cabinet, 5 loopful of Bacillus subtilis bacteria colonies were inoculated into the tryptic soy broth. This step was repeated for the other three bacteria which were inoculated in the nutrient broth. These broths were incubated for 24 hours at the temperature of $37^{\circ} \mathrm{C}$ in an incubator. Then, these broths that contained bacteria strains were centrifuged at 5000rpm for 10 minutes. The supernatant was discarded and the cell pellet formed was collected and re- suspended in the sterile nutrient broth and tryptic soy broth. By using the UV spectrophotometer, the seeded broths were standardized to the value 0.5 of the absorbance according to McFarland standard at the wavelength of $517 \mathrm{~nm}$.

Serial Dilution of Minimum Inhibitory Concentration (MIC) Assay: Before starting the MIC assay, the biosafety cabinet was 
sanitized with $70 \%$ alcohol and the UV light was switched on for 10 minutes. $2.5 \mathrm{~g}$ of plant extract was measured using an analytical balance and mixed with $25 \mathrm{ml}$ of $0.5 \%$ DMSO, forming the stock solution with a concentration of $10 \mathrm{mg} / \mathrm{ml}$. The mixtures with the concentration of $50,25,12.5,6.25,3.125,1.5625 \mathrm{mg} / \mathrm{ml}$ were formed upon two-fold serial dilution. $2 \mathrm{ml}$ of the stock solution and $2 \mathrm{ml}$ of the standard McFarland seeded broth were taken by using a micropipette and mixed in the sterilized test tube, thus obtained a concentration of $50 \mathrm{mg} / \mathrm{ml} .2 \mathrm{ml}$ of the stock solution and $2 \mathrm{ml}$ from the first test tube were taken by using a micropipette and mixed in the sterilized test tube, thus obtained a concentration of $25 \mathrm{mg} /$ $\mathrm{ml} .2 \mathrm{ml}$ of the stock solution and $2 \mathrm{ml}$ from the second test tube were taken by using a micropipette and mixed in the sterilized test tube, thus obtained a concentration of $12.5 \mathrm{mg} / \mathrm{ml} .2 \mathrm{ml}$ of the stock solution and $2 \mathrm{ml}$ from the third test tube were taken by using a micropipette and mixed in the sterilized test tube, thus obtained a concentration of $6.25 \mathrm{mg} / \mathrm{ml} .2 \mathrm{ml}$ of the stock solution and $2 \mathrm{ml}$ from the fourth test tube were taken by using a micropipette and mixed in the sterilized test tube, thus obtained a concentration of $3.125 \mathrm{mg} / \mathrm{ml} .2 \mathrm{ml}$ of the stock solution and $2 \mathrm{ml}$ from the fifth test tube were taken by using a micropipette and mixed in the sterilized test tubes. $2 \mathrm{ml}$ of the mixture was pipetted and discarded, thus obtained a concentration of $1.5625 \mathrm{mg} / \mathrm{ml}$. The positive tube that contained seeded broth and the negative tube that contained sterile nutrient or tryptic soy broth were prepared accordingly. The micropipette tips were discarded after finished transferring each set of test tubes. These tubes were fitted with cotton wool and covered with double-folded aluminium foil the tubes were incubated for 24 hours at the temperature of $37^{\circ} \mathrm{C}$. The turbidity of each of the tubes were observed and recorded.

Phytochemical Screening of Ethanolic CPS Extract: The CPS were extracted with $95 \%$ ethanol, and the plant extract was undergone phytochemical screening. In the present study, the results obtained for the phytochemical screening of $C$. papaya seed ethanolic extract was analysed and it was found out that alkaloids, anthraquinone, carbohydrate and flavonoids were present in the sample. The alkaloid content was tested with Mayer's and Wagner's reagent. Mayer's reagent is an alkaloidal precipitating reagent which its function is to determine the presence of alkaloids in natural products. Most alkaloids will be precipitated in a neutral or slightly acidic solution owing to Mayer's reagent, cream colour precipitate will be obtained upon observation. The ethanolic extract of CPS showed positive results for both Mayer's and Wagner's tests, which indicates the CPS contained alkaloids component. The rest of all the phytochemicals are listed in Table 3.

Table 3: Results of Phytochemical Screening.

\begin{tabular}{|c|c|c|}
\hline \multirow{2}{*}{ S. No } & Analysis Test & Ethanolic \\
\cline { 3 - 3 } & & Soxhlet Extract \\
\hline 1 & Mayer's Test (Alkaloid Test) & + \\
\hline 2 & Wagner's Test (Alkaloid Test) & + \\
\hline 3 & Tannins Test & - \\
\hline
\end{tabular}

\begin{tabular}{|c|r|c|}
\hline 4 & Anthraquinones Test & + \\
\hline 5 & Glycosides Test & - \\
\hline 6 & Barfoed's Test (Reducing Sugar test) & + \\
\hline 7 & Molisch's Test (Reducing Sugar Test) & - \\
\hline 8 & Fehling's Test (Reducing Sugar Test) & + \\
\hline 9 & Saponin Test & - \\
\hline 10 & Flavonoids Test & - \\
\hline 11 & Salkowski Test (Terpenoids Test) & + \\
\hline \multirow{2}{*}{12} & Liebermann Burchard Test & (Terpenoids Test) \\
\cline { 2 - 3 } & &
\end{tabular}

Note: $(+)=$ positive,$(-)=$ negative .

\section{Results and Discussion}

(Table 3)

\section{Antioxidant Assay}

Determination of Total Phenolic Content (TPC): In this research, the antioxidant potential of the C. papaya seeds was determined by using DPPH free radicals scavenging method and BHT was used as a standard. The DPPH is a stable free-radicals which has a colour of purple, as the antioxidants react with the DPPH, the DPPH will be converted into non-radical DPPH-H form. Besides that, the colour of the DPPH will be decolourised from purple to light yellow colour. The degree of decolourisation indicates the potency of the plant extracts in scavenging the free radicals.

$$
\begin{gathered}
(\mathrm{DPPH})+\mathrm{H}-\mathrm{A} \rightarrow \\
\text { (Purple) } \quad \text { (Yellow) }
\end{gathered}
$$

Subsequently, the plant extract was prepared in the concentration of 10, 20, 40, 60,80 and $100 \mu \mathrm{g} / \mathrm{ml}$ and mixed with the DPPH, the absorbance was determined at $518 \mathrm{~nm}$ after kept the tubes in the dark for 30 minutes.

Phenolic compounds are very essential plant constituents which responsible for the antioxidant activity due to its redox properties. As a basis, Folin-Ciocalteu reagent was used to measure the phenolic content of different concentrations of plant extract. In this test, the Gallic acid was used as a standard and the total phenolic content was calculated by using the formula $\mathrm{C}=(\mathrm{A} / \mathrm{B}) \mathrm{x}$ dilution factor. The results were derived from the calibration curve of Gallic acid, it was expressed as Gallic acid equivalents (GAE) per gram of samples. In the present study, the total phenolic content found was $6.420 \mathrm{mg} \mathrm{GAE} / \mathrm{g}$ and $6.097 \mathrm{mg} \mathrm{GAE} / \mathrm{g}$ for the concentrations of 50 and $200 \mu \mathrm{g} / \mathrm{ml}$ respectively. The following formula was used for the antioxidant activity determination.

$$
\text { DPPH Radical Scavenging Activity (\%) }=\frac{\text { Acontrol }- \text { Asample }}{\text { Acontrol }} \times 100
$$

The concentration and absorbance of Gallic acid determined by U.V and concentration of CPS ethanolic absorbance is shown in Tables 4 \& 5 and graphs are shown in Figures 3 \& 4, respectively. 
The concentration, absorbance and the corresponding percentage of scavenging of BHT for DPPH Free Radical Scavenging Assay is shown in Table 6. The concentration, absorbance and the corresponding percentage of scavenging of ethanolic CPS extract is placed in Table 7 while Graph of percentage scavenging against the standard concentration is drawn in Figure 5. The Figure 6 is indicating percentage scavenging against the sample concentration.

Graph of concentration Against UV Absorbance of Gallic Acid

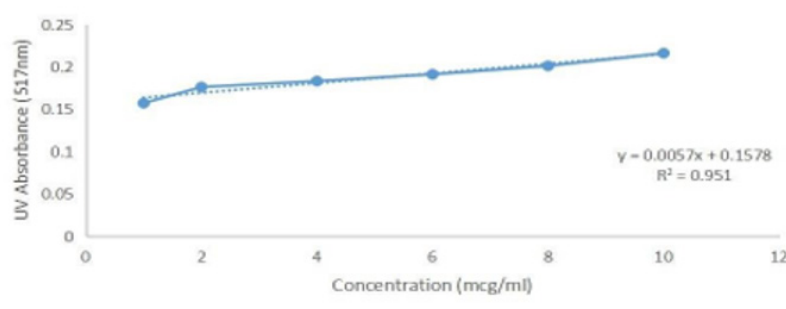

$\rightarrow$ Absorbance $(\mathrm{S} 17 \mathrm{~nm})$.......... Linear (Absorbance $(517 \mathrm{~nm}))$

Figure 3: Graph of concentration and corresponding absorbance of Gallic acid.

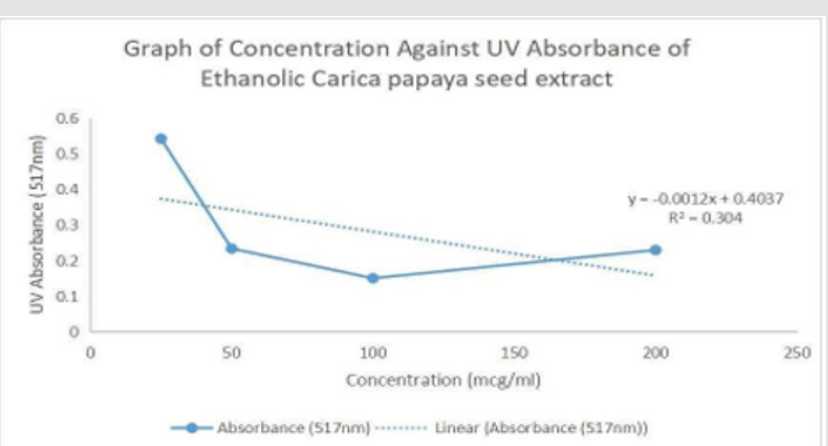

Figure 4: Graph of concentration and corresponding absorbance of ethanolic C. papaya seed extract.

Graph of Percentage Scavenging Against Standard Concentration

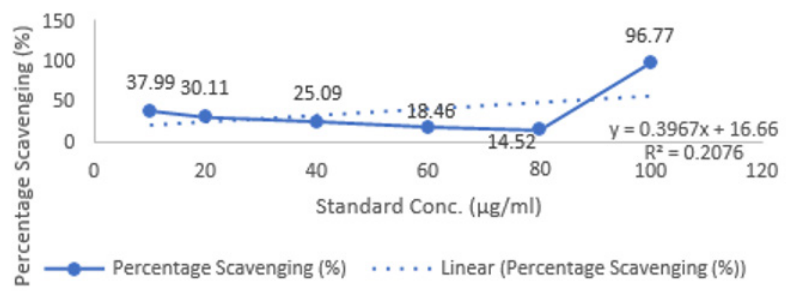

Figure 5: Graph of percentage scavenging against the standard concentration.

Table 4: Concentration and absorbance of Gallic acid determined by the UV Spectrophotometer.

\begin{tabular}{|c|c|}
\hline Concentration $(\boldsymbol{\mu g} / \mathbf{m l})$ & Absorbance $(\mathbf{5 1 7 n m})$ \\
\hline 1 & 0.157 \\
\hline 2 & 0.176 \\
\hline
\end{tabular}

\begin{tabular}{|c|c|}
\hline 4 & 0.183 \\
\hline 6 & 0.191 \\
\hline 8 & 0.201 \\
\hline 10 & 0.216 \\
\hline
\end{tabular}

\section{Graph of Percentage Scavenging Against}

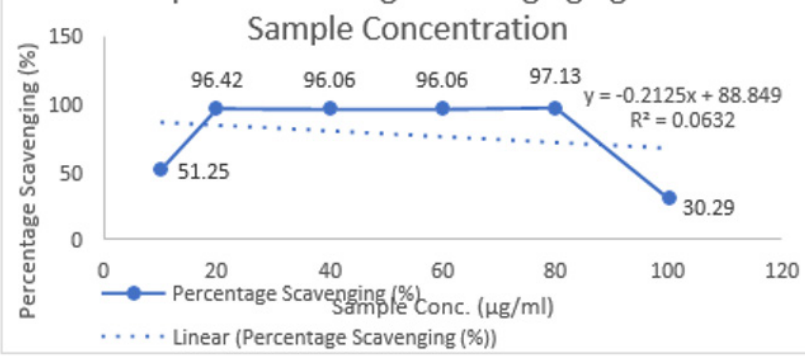

Figure 6: Graph of percentage scavenging against the sample concentration.

Table 5: Concentration and absorbance of Ethanolic CPS extract.

\begin{tabular}{|c|c|}
\hline Concentration $(\boldsymbol{\mu g} / \mathbf{m l})$ & Absorbance $(\mathbf{5 1 7} \mathbf{n m})$ \\
\hline 25 & 0.541 \\
\hline 50 & 0.233 \\
\hline 100 & 0.15 \\
\hline 200 & 0.229 \\
\hline
\end{tabular}

Table 6: The concentration, absorbance and the corresponding percentage of scavenging of BHT (butylated hydroxytoluene).

\begin{tabular}{|c|c|c|}
\hline $\begin{array}{c}\text { Concentration } \\
(\boldsymbol{\mu g} / \mathbf{m l})\end{array}$ & Standard Absorbance & \multirow{2}{*}{$\begin{array}{c}\text { Percentage of } \\
\text { Scavenging (\%) }\end{array}$} \\
\cline { 2 - 3 } & $\mathbf{( 5 1 8 n \mathbf { n } )}$ & $37.99 \%$ \\
\hline 10 & 0.346 & $30.11 \%$ \\
\hline 20 & 0.39 & $25.09 \%$ \\
\hline 40 & 0.418 & $18.46 \%$ \\
\hline 60 & 0.455 & $14.52 \%$ \\
\hline 80 & 0.477 & $96.77 \%$ \\
\hline 100 & 0.018 & \\
\hline
\end{tabular}

Table 7: The concentration, absorbance and the corresponding percentage of scavenging of ethanolic CPS extract.

\begin{tabular}{|c|c|c|}
\hline $\begin{array}{c}\text { Concentration } \\
(\boldsymbol{\mu g} / \mathbf{m l})\end{array}$ & $\begin{array}{c}\text { Sample Absorbance } \\
(\mathbf{5 1 8 n m})\end{array}$ & $\begin{array}{c}\text { Percentage of } \\
\text { Scavenging (\%) }\end{array}$ \\
\hline 10 & 0.272 & $51.25 \%$ \\
\hline 20 & 0.02 & $96.42 \%$ \\
\hline 40 & 0.022 & $96.06 \%$ \\
\hline 60 & 0.022 & $96.06 \%$ \\
\hline 80 & 0.016 & $97.13 \%$ \\
\hline 100 & 0.389 & $30.29 \%$ \\
\hline
\end{tabular}

\section{DPPH Free Radical Scavenging Assay}

Antimicrobial Assay: Tables 8-15 are laid down to show the Zone of Inhibition of Escherichia coli in comparison to Penicillin; the Zone of Inhibition of Escherichia coli in comparison to Ciprofloxacin: Zone of Inhibition of Staphylococcus aureus in comparison to Penicillin; Zone of Inhibition of Staphylococcus 
aureus in comparison to Ciprofloxacin; Zone of Inhibition of Salmonella typhi in comparison to Penicillin; Zone of Inhibition of Salmonella typhi in comparison to Ciprofloxacin; Zone of Inhibition of Bacillus subtilis in comparison to Penicillin and concentration $(\mathrm{mg} / \mathrm{ml})$ against the diameter of zone of inhibition ( $\mathrm{mm}$ ), respectively (Figure 7). The Figures 8-18 are showing the inhibition by various standards in relation to different bacteria cultures. The detail is mentioned after every figure underneath.

Table 8: Zone of Inhibition of Escherichia coli in comparison to Penicillin.

\begin{tabular}{|c|c|c|c|c|c|}
\hline \multirow{2}{*}{\multicolumn{2}{|c|}{ Concentration $(\mathrm{mg} / \mathrm{ml})$}} & \multicolumn{4}{|c|}{ Diameter of Zone of Inhibition (mm) } \\
\hline & & \multirow{2}{*}{$\begin{array}{c}\text { Set } 1 \\
-\end{array}$} & \multirow{2}{*}{$\begin{array}{c}\text { Set } 2 \\
-\end{array}$} & \multirow{2}{*}{$\begin{array}{c}\text { Set } 3 \\
-\end{array}$} & \multirow{2}{*}{$\begin{array}{c}\text { Average } \\
-\end{array}$} \\
\hline \multirow{6}{*}{ Plant Extract } & 1 & & & & \\
\hline & 2 & - & - & - & - \\
\hline & 4 & - & - & - & - \\
\hline & 6 & - & - & - & - \\
\hline & 8 & - & - & - & - \\
\hline & 10 & - & - & - & - \\
\hline Penicillin & 5 & 2.9 & 3 & 3.4 & 3.1 \\
\hline \multicolumn{2}{|c|}{ DMSO (0.5\%) } & - & - & - & - \\
\hline
\end{tabular}

Table 9: Zone of Inhibition of Escherichia coli in comparison to Ciprofloxacin.

\begin{tabular}{|c|c|c|c|c|c|}
\hline \multirow{2}{*}{ Concentration (mg/ml) } & \multicolumn{4}{|c|}{ Diameter of Zone of Inhibition (mm) } \\
\cline { 2 - 6 } & 1 & Set 1 & Set 2 & Set 3 & Average \\
\hline & 2 & - & - & - & - \\
\cline { 2 - 6 } & 4 & - & - & - & - \\
\cline { 2 - 6 } & 6 & - & - & - & - \\
\cline { 2 - 6 } & 8 & - & - & - & - \\
\cline { 2 - 6 } & 10 & - & - & - & - \\
\hline Plant Extract & 5 & 3.6 & 3.8 & 3.3 & 3.57 \\
\hline DMSO (0.5\%) & & - & - & - & - \\
\hline
\end{tabular}

Table 10: Zone of Inhibition of Staphylococcus aureus in comparison to Penicillin.

\begin{tabular}{|c|c|c|c|c|c|}
\hline \multirow{2}{*}{\multicolumn{2}{|c|}{$\begin{array}{c}\text { Concentration } \\
(\mathrm{mg} / \mathrm{ml})\end{array}$}} & \multicolumn{4}{|c|}{ Diameter of Zone of Inhibition (mm) } \\
\hline & & \multirow{2}{*}{$\begin{array}{c}\text { Set } 1 \\
-\end{array}$} & \multirow{2}{*}{$\begin{array}{c}\text { Set } 2 \\
-\end{array}$} & \multirow{2}{*}{$\begin{array}{c}\text { Set } 3 \\
-\end{array}$} & \multirow{2}{*}{$\begin{array}{c}\text { Average } \\
-\end{array}$} \\
\hline \multirow{6}{*}{ Plant Extract } & 1 & & & & \\
\hline & 2 & - & - & - & - \\
\hline & 4 & - & - & - & - \\
\hline & 6 & - & - & - & - \\
\hline & 8 & - & - & - & - \\
\hline & 10 & - & - & - & - \\
\hline Penicillin & 5 & 3.4 & 3.5 & 3.5 & 3.47 \\
\hline \multicolumn{2}{|c|}{ DMSO (0.5\%) } & - & - & - & - \\
\hline
\end{tabular}

Table 11: Zone of Inhibition of Staphylococcus aureus in comparison to Ciprofloxacin.

\begin{tabular}{|c|c|c|c|c|c|}
\hline \multirow{2}{*}{ Concentration $(\mathbf{m g} / \mathbf{m l})$} & \multicolumn{4}{|c|}{ Diameter of Zone of Inhibition (mm) } \\
\cline { 2 - 6 } & 1 & Set 1 & Set 2 & Set 3 & Average \\
\hline \multirow{4}{*}{ Plant Extract } & 2 & - & - & - & - \\
\cline { 2 - 6 } & 4 & - & - & - & - \\
\cline { 2 - 6 } & 6 & - & - & - & - \\
\cline { 2 - 6 } & 8 & - & - & - & - \\
\cline { 2 - 6 } & 10 & - & - & - & - \\
\hline Ciprofloxacin & 5 & 2.0 & 2.0 & 2.0 & 2.0 \\
\hline DMSO (0.5\%) & & - & - & - & - \\
\hline
\end{tabular}

Table 12: Zone of Inhibition of Salmonella typhi in comparison to Penicillin.

\begin{tabular}{|c|c|c|c|c|c|}
\hline \multirow{2}{*}{\multicolumn{2}{|c|}{$\begin{array}{c}\text { Concentration } \\
(\mathrm{mg} / \mathrm{ml})\end{array}$}} & \multicolumn{4}{|c|}{ Diameter of Zone of Inhibition (mm) } \\
\hline & & \multirow{2}{*}{$\begin{array}{c}\text { Set } 1 \\
-\end{array}$} & \multirow{2}{*}{$\begin{array}{c}\text { Set } 2 \\
-\end{array}$} & \multirow{2}{*}{$\begin{array}{c}\text { Set } 3 \\
-\end{array}$} & \multirow{2}{*}{$\begin{array}{c}\text { Average } \\
-\end{array}$} \\
\hline \multirow{6}{*}{ Plant Extract } & 1 & & & & \\
\hline & 2 & - & - & - & - \\
\hline & 4 & - & - & - & - \\
\hline & 6 & - & - & - & - \\
\hline & 8 & - & - & - & - \\
\hline & 10 & - & - & - & - \\
\hline Penicillin & 5 & 1.6 & - & 1.8 & 1.7 \\
\hline \multicolumn{2}{|c|}{ DMSO $(0.5 \%)$} & - & - & - & - \\
\hline
\end{tabular}

Table 13: Zone of Inhibition of Salmonella typhi in comparison to Ciprofloxacin.

\begin{tabular}{|c|c|c|c|c|c|}
\hline \multirow{2}{*}{\multicolumn{2}{|c|}{ Concentration $(\mathrm{mg} / \mathrm{ml})$}} & \multicolumn{4}{|c|}{ Diameter of Zone of Inhibition (mm) } \\
\hline & & \multirow{2}{*}{$\begin{array}{c}\text { Set } 1 \\
-\end{array}$} & \multirow{2}{*}{$\begin{array}{c}\text { Set } 2 \\
-\end{array}$} & \multirow{2}{*}{$\begin{array}{c}\text { Set } 3 \\
- \\
\end{array}$} & \multirow{2}{*}{$\begin{array}{c}\text { Average } \\
-\end{array}$} \\
\hline \multirow{6}{*}{ Plant Extract } & 1 & & & & \\
\hline & 2 & - & - & - & - \\
\hline & 4 & - & - & - & - \\
\hline & 6 & - & - & - & - \\
\hline & 8 & - & - & - & - \\
\hline & 10 & - & - & - & - \\
\hline Ciprofloxacin & 5 & 3.0 & 3.2 & 3.4 & 3.2 \\
\hline \multicolumn{2}{|c|}{ DMSO $(0.5 \%)$} & - & - & - & - \\
\hline
\end{tabular}

Table 14: Zone of Inhibition of Bacillus subtilis in comparison to Penicillin.

\begin{tabular}{|c|c|c|c|c|c|}
\hline \multirow{2}{*}{ Concentration $(\mathrm{mg} / \mathrm{ml})$} & \multicolumn{4}{|c|}{ Diameter of Zone of Inhibition (mm) } \\
\cline { 2 - 6 } & Set 1 & Set 2 & Set 3 & Average \\
\hline \multirow{7}{*}{ Plant Extract } & 1 & - & - & - & - \\
\cline { 2 - 6 } & 2 & - & - & - & - \\
\cline { 2 - 6 } & 4 & - & - & - & - \\
\cline { 2 - 6 } & 6 & - & - & - & - \\
\cline { 2 - 6 } & 8 & - & - & - & - \\
\cline { 2 - 6 } & 10 & - & - & - & - \\
\hline
\end{tabular}




\begin{tabular}{|l|l|c|c|c|c|}
\hline Penicillin & 5 & 2.5 & 3.0 & 2.5 & 2.67 \\
\hline \multicolumn{2}{|c|}{ DMSO (0.5\%) } & - & - & - & - \\
\hline
\end{tabular}

Table 15.

\begin{tabular}{|c|c|c|c|c|c|}
\hline \multirow{2}{*}{ Concentration (mg/ml) } & \multicolumn{4}{|c|}{ Diameter of Zone of Inhibition (mm) } \\
\cline { 2 - 6 } & & Set 1 & Set 2 & Set 3 & Average \\
\hline \multirow{4}{*}{ Plant Extract } & 1 & - & - & - & - \\
\cline { 2 - 6 } & 2 & - & - & - & - \\
\cline { 2 - 6 } & 4 & - & - & - & - \\
\cline { 2 - 6 } & 6 & - & - & - & - \\
\cline { 2 - 6 } & 8 & - & - & - & - \\
\hline \multirow{3}{*}{ Ciprofloxacin } & 5 & 2.8 & 2.8 & 2.6 & 2.73 \\
\hline DMSO (0.5\%) & & - & - & - & - \\
\hline
\end{tabular}
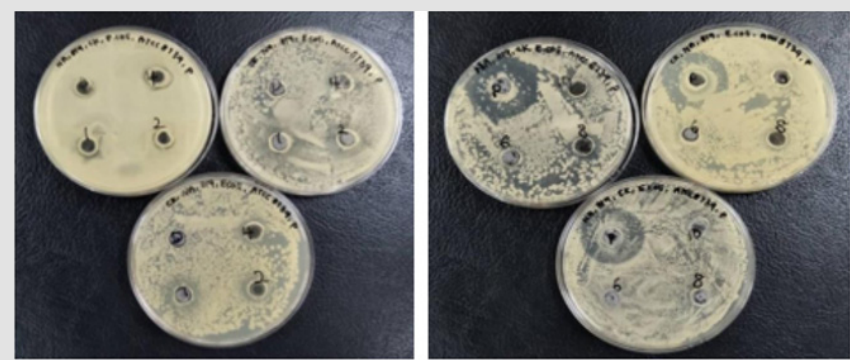

Figure 7: The figure shows no zone of inhibition observed for the $E$. coli bacteria culture, except clear zone of inhibition at the vicinity of penicillin wells.
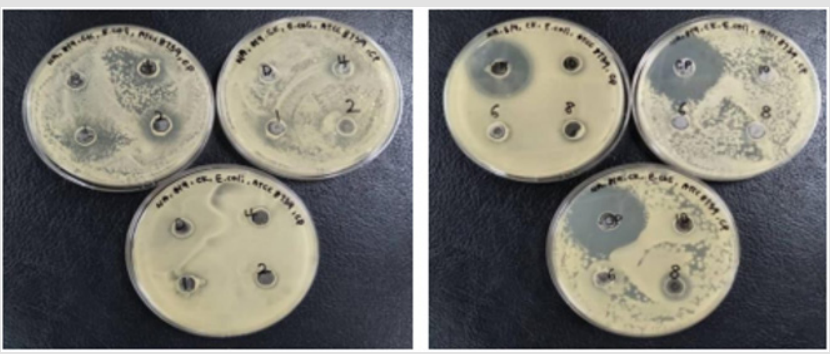

Figure 8: The figure shows no zone of inhibition observed for the $E$. coli bacteria culture, except clear zone of inhibition at the vicinity of ciprofloxacin wells.

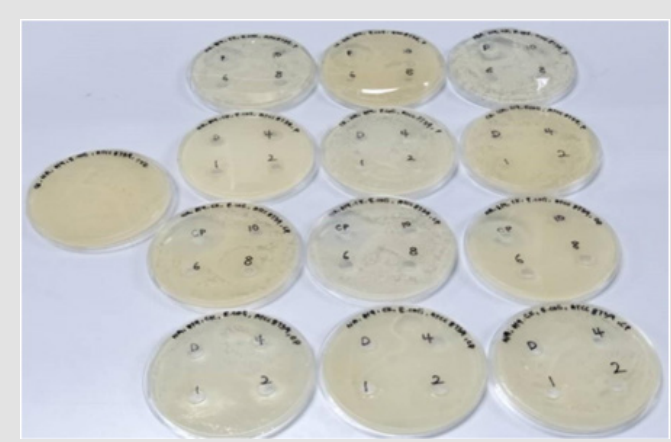

Figure 9: The petri plates cultivated with E. coli against plant extract, DMSO, penicillin and ciprofloxacin. The sets including positive plate.
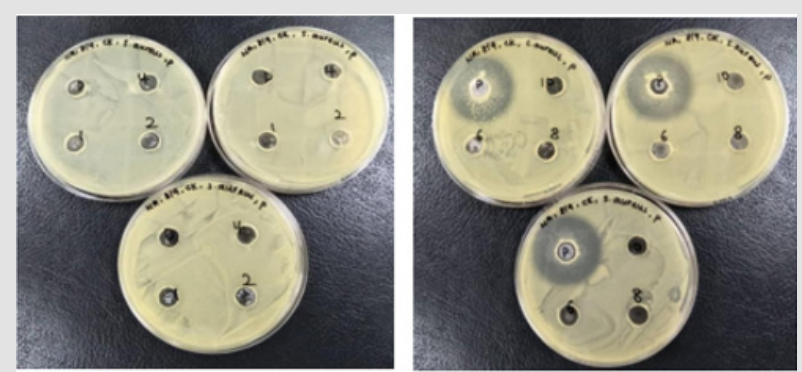

Figure 10: The figure shows no zone of inhibition observed for the $S$. aureus bacteria culture, except clear zone of inhibition at the vicinity of penicillin wells.
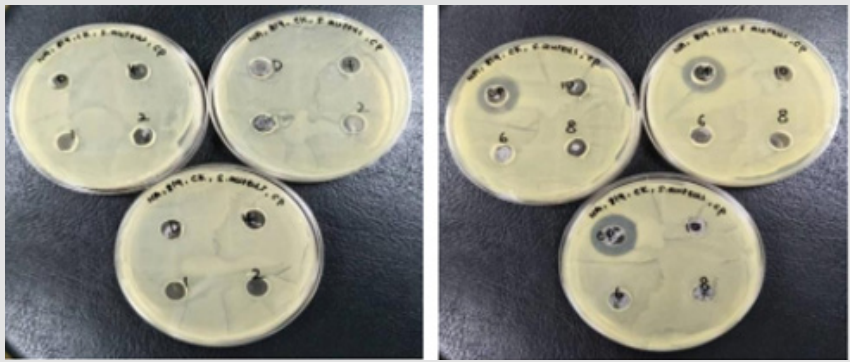

Figure 11: The figure shows no zone of inhibition observed for the $S$. aureus bacteria culture, except clear zone of inhibition at the vicinity of penicillin wells.

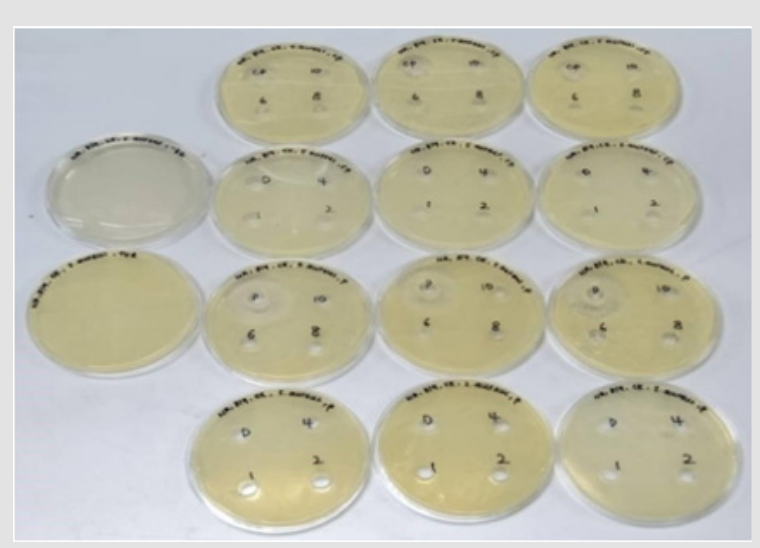

Figure 12: The petri plates cultivated with S. aureus against plant extract, DMSO, penicillin and ciprofloxacin. The sets including positive and negative plates.
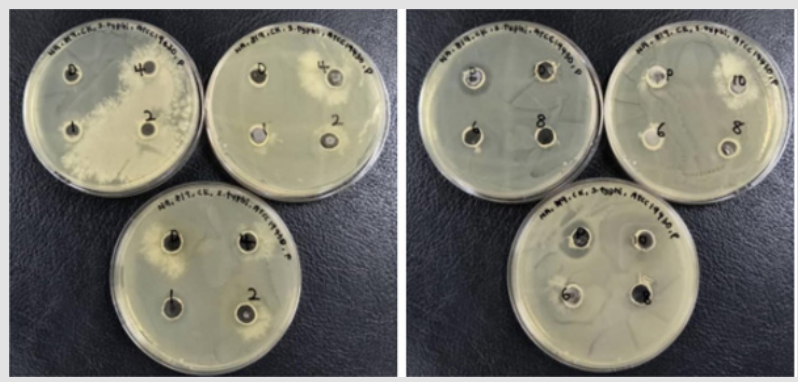

Figure 13: The figure shows no zone of inhibition observed for the $S$. typhi bacteria culture, except clear zone of inhibition at the vicinity of penicillin wells. 


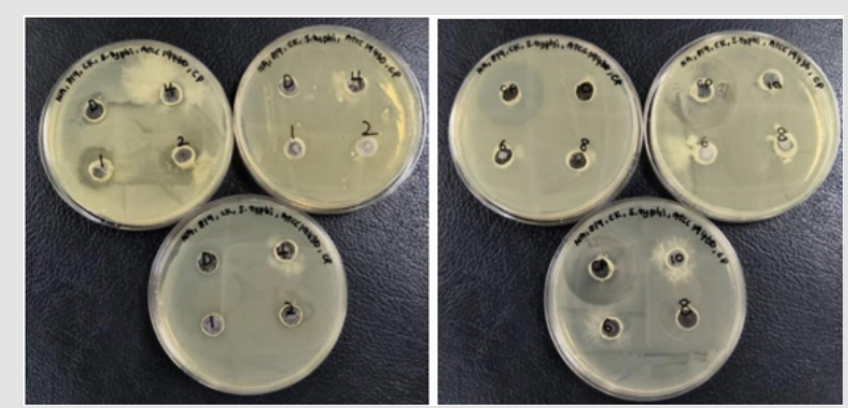

Figure 14: The figure shows no zone of inhibition observed for the S. typhi bacteria culture, except clear zone of inhibition at the vicinity of penicillin wells.

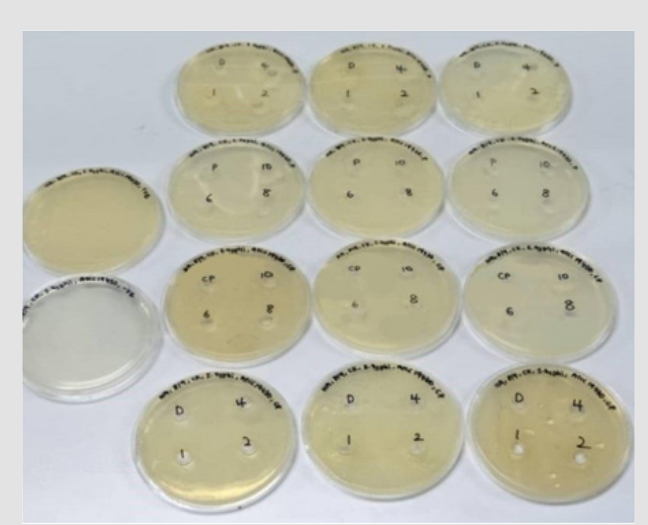

Figure 15: The petri plates cultivated with S. typhi against plant extract, DMSO, penicillin and ciprofloxacin. The sets including positive and negative plates.

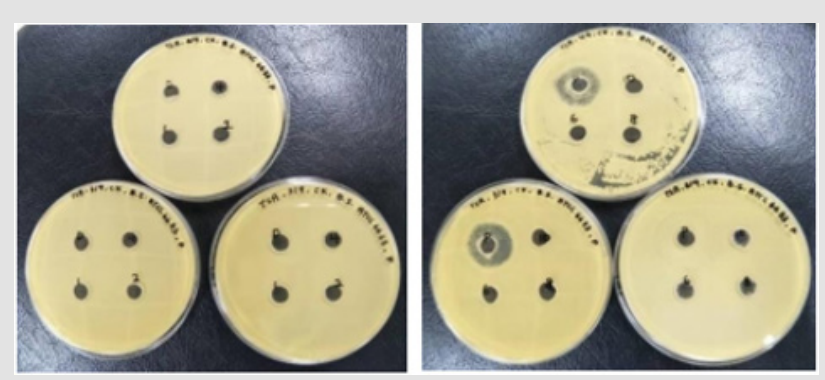

Figure 16: The figure shows no zone of inhibition observed for the $B$. subtilis bacteria culture, except clear zone of inhibition at the vicinity of penicillin wells.

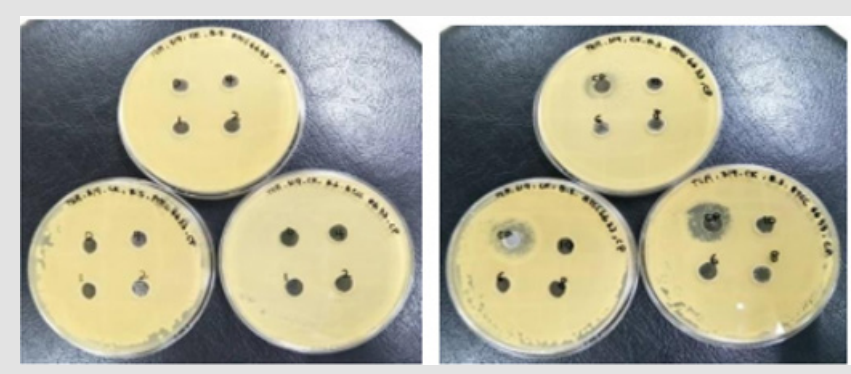

Figure 17: The figure shows no zone of inhibition observed for the $B$. subtilis bacteria culture, except clear zone of inhibition at the vicinity of penicillin wells.

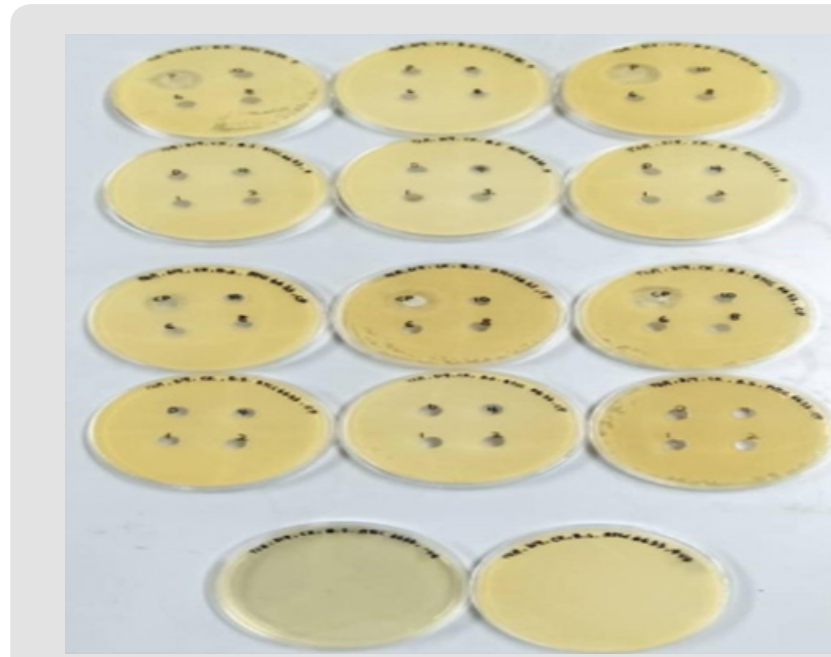

Figure 18: The petri plates cultivated with $B$. subtilis against plant extract, DMSO, penicillin and ciprofloxacin. The sets including positive and negative plates.

\section{Discussion}

One of the objectives of this research was to determine the phytochemical properties of Carica papaya seeds. The Carica papaya seeds were extracted with $95 \%$ ethanol and the plant extract was undergone phytochemical screening. The presence of phytochemicals is a marker that the plant can be an essential source of precursors in the formation of newer synthetic drugs. In the present study, the results obtained for the phytochemical screening of $C$. papaya seed ethanolic extract was analysed and it was found out that alkaloids, anthraquinone, carbohydrate and flavonoids were present in the sample. Moreover, the extractive value estimation should be carried out to determine the amount of the active constituents in a given amount of plant material and identify which extraction solvent is more suitable for the given plant sample. By using this method, phytochemicals present in the plant sample can be extracted maximally. Phenolic compounds are very essential plant constituents which responsible for the antioxidant activity due to its redox properties. As a basis, Folin-Ciocalteu reagent was used to measure the phenolic content of different concentrations of plant extract. In this test, the Gallic acid was used as a standard and the total phenolic content was calculated by using the formula $\mathrm{C}=(\mathrm{A} / \mathrm{B}) \mathrm{x}$ dilution factor. The results were derived from the calibration curve of Gallic acid, it was expressed as Gallic acid equivalents (GAE) per gram of samples. In the present study, the total phenolic content found was $6.420 \mathrm{mg} \mathrm{GAE} / \mathrm{g}$ and 6.097 $\mathrm{mg} \mathrm{GAE} / \mathrm{g}$ for the concentrations of 50 and $200 \mu \mathrm{g} / \mathrm{ml}$ respectively.

In this research work, the antioxidant potential of the C. papaya seeds was determined by using DPPH free radicals scavenging method and BHT was used as a standard. The DPPH is a stable freeradicals which has a colour of purple, as the antioxidants react with the DPPH, the DPPH will be converted into non-radical DPPH-H form. Besides that, the colour of the DPPH will be decolourised from purple to light yellow colour. The degree of decolourisation 
indicates the potency of the plant extracts in scavenging the free radicals. According to the results obtained, the IC50 was calculated for the BHT. The antibacterial activity of $C$. papaya seeds was tested by using the Escherichia coli, Staphylococcus aureus, Salmonella typhi, and Bacillus subtilis. The extract concentrations used in the agar well diffusion method were $0.1,0.2,0.4,0.6,0.8$ and $1.0 \mathrm{mg} /$ $\mathrm{ml}$, other than that, $5 \mathrm{mg} / \mathrm{ml}$ of penicillin and ciprofloxacin was playing the role as a standard in this study. In the present study, there was no zone of inhibition observed in all concentrations of ethanolic $C$. papaya seed extract. The microorganism used were all in active condition, this can be proven as the ciprofloxacin as well as penicillin showed a clear zone of inhibition. In addition, the bacteria strains utilised were susceptible towards $C$. papaya seeds as stated by Jyotsna Kiran Peter et al. [26] and Kelechi Mary et al. (2018), therefore it was concluded that the extracts have no antibacterial activity at the concentration of $0.1,0.2,0.4,0.6,0.8$ and $1.0 \mathrm{mg} / \mathrm{ml}$. In the case of MIC test, the plant extract with the concentration of $0.1,0.2,0.4,0.6,0.8$ and $1.0 \mathrm{mg} / \mathrm{ml}$ were utilised. However, there was no clear solution observed for all MIC tubes, which indicates the C. papaya seed extract has no antibacterial potential. As there was no MIC activity observed, thus the MBC test was not performed in this study.

\section{Conclusion}

In conclusion, the phytochemical screening of ethanolic extracts of Carica papaya seeds had determined the presence of alkaloids, flavonoids, carbohydrates and anthraquinones. The antibacterial activity of Carica papaya seeds was determined by using the agar well diffusion and MIC assay. The microorganism used were Escherichia coli, Staphylococcus aureus, Salmonella typhi, and Bacillus subtilis. There was no antibacterial activity observed in the agar well diffusion method and the MIC assay. The antioxidant activity of the plant extract was assessed through the method of DPPH test while the total amount of phenolic compounds in the extract can be determined through the TPC test. It was suggested that seeds of Carica papaya can be a potential source as a natural significant antioxidant and marked antimicrobial agent. The $C$. papaya seeds is a natural source that worth for further explore as it is inexpensive, natural, harmless and easy to obtain.

\section{Interests of Conflict}

The authors declare that there is no conflict of interests in the present publication.

\section{Acknowledgement}

Faculty of Pharmacy, AIMST University is greatly appreciated for providing financial assistance and complete laboratory facilities at AIMST University, Bedong, Kedah D.A, Malaysia, in completion of this research project.

\section{References}

1. Subenthiran S, Choon TC, Cheong KC, Thayan R, Teck MB, et al. (2013) Carica papaya leaves juice significantly accelerates the rate of increase in platelet count among patients with dengue fever and dengue haemorrhagic fever. Evidence-Based Complementary and Alternative Medicine 2013(16): 616737.

2. Aravind G, Bhowmik D, Duraivel S, Harish G (2013) Traditional and medicinal uses of Carica papaya. Journal of Medicinal Plants Studies 1: 7-15.

3. Banu KS, Cathrine DL (2015) General Techniques Involved in Phytochemical Analysis. Int J Adv Res Chem Sci 2(4): 25-32.

4. Ray PD, Huang B-W, Tsuji Y (2012) Reactive oxygen species (ROS) homeostasis and redox regulation in cellular signaling. Cell Signal 24(5): 981-990.

5. Xu DP, Li Y, Meng X, Zhou T, Zhou Y, et al. (2017) Natural antioxidants in foods and medicinal plants: Extraction, assessment and resources. International journal of molecular sciences 18(1): 96.

6. Kedare SB, Singh RP (2011) Genesis and development of DPPH method of antioxidant assay. J Food Sci Technol 48(4): 412-422.

7. Adejuwon AO, Agbaje EO, Idika N (2011) Antifungal and antibacterial activities of aqueous and methanolic root extracts of Carica papaya linn. (Caricaceae). International Research Journal of Microbiology 2(8): 270277.

8. Rather IA, Kim B-C, Bajpai VK, Park Y-H (2017) Self-medication and antibiotic resistance: Crisis, current challenges, and prevention. Saudi J Biol Sci 24(4): 808-812.

9. Alabi OA, Haruna MT, Anokwuru CP, Jegede T, Abia H, et al. (2012) Comparative studies on antimicrobial properties of extracts of fresh and dried leaves of Carica papaya (L) on clinical bacterial and fungal isolates.

10. Kelechi M, Ukaegbu-Obi K, Chisom P, Enya (2018) antibacterial activity of carica papaya seeds on some human pathogens Annals of West University of Timişoara, ser Biology 21(1): 11-16.

11. Francis E, Jose V (2016) The Antibacterial Effect of Carica papaya L. Extracts and Their Synergistic Effect with Antibiotic and Non-antibiotic Drugs. Br Microbiol Res J 16(4): 1-11.

12. Mwesigwa B, Dominguez G, Valladares M, Katawera V, Nkwangu D, et al. (2015) Antibacterial effect of crude methanol Carica papaya L. (papaya) extract and amoxicillin combination. Cuban J Med Plants.

13. Masfufatun M, Putri N (2019) Antimicrobial assay of papaya seed ethanol extract (Carica papaya Linn) and phytochemical analysis of its active compounds. J Phys Conf Ser 1277: 012018.

14. Naggayi M, Mukiibi N, Iliya E (2015) The protective effects of aqueous extract of Carica papaya seeds in paracetamol induced nephrotoxicity in male wistar rats. Afr Health Sci 15(2): 598-605.

15. Panzarini E, Dwikat M, Mariano S, Vergallo C, Dini L (2014) Administration dependent antioxidant effect of Carica papaya seeds water extract. Evidence-Based Complementary and Alternative Medicine 2014(3): 281508.

16. Zhou K, Wang H, Mei W, Li X, Luo Y, et al. (2011) Antioxidant Activity of Papaya Seed Extracts. Molecules 16(8): 6179-6192.

17. Ajayi IA, Ajibade O, Oderinde RA (2011) Preliminary phytochemical analysis of some plant seeds. Res J Chem Sci 1(3): 58-62.

18. Matuszewska A, Jaszek M, Stefaniuk D, Ciszewski T, Matuszewski Ł (2018) Anticancer, antioxidant, and antibacterial activities of low molecular weight bioactive sub-fractions isolated from cultures of wood degrading fungus Cerrena unicolor. PLOS ONE 13(6): e0197044.

19. Paur I, Carlsen MH, Halvorsen BL, Blomhoff R (2011) Antioxidants in Herbs and Spices: Roles in Oxidative Stress and Redox Signaling. In: 
Benzie IFF, Wachtel-Galor S (Eds.,)., Herbal Medicine: Biomolecular and Clinical Aspects [Internet] ( $2^{\text {nd }}$ Edn.,), Boca Raton (FL): CRC Press/Taylor \& Francis.

20. Barroso PTW, de Carvalho PP, Rocha TB, Pessoa FLP, Azevedo DA, et al. (2016) Evaluation of the composition of Carica papaya L. seed oil extracted with supercritical $\mathrm{CO}_{2}$. Biotechnol Rep 11: 110-116.

21. Eyo J (2013) Toxicity and Effect of Carica Papaya Seed Aqueous Extract on Liver Biomarkers of Clarias Gariepinus. Int J Indig Med Plants 46(3): 1301-1307.

22. Devi P S S, Kumar N (2017) The surprising health benefits of papaya seeds: A review. 6: 424-429.

ISSN: 2574-1241

DOI: 10.26717/BJSTR.2021.33.005459

Naeem Hasan Khan. Biomed J Sci \& Tech Res

(C) (P) This work is licensed under Creative

Submission Link: https://biomedres.us/submit-manuscript.php
23. Dawkins G, Hewitt H, Wint Y, Obiefuna PC, Wint B (2003) Antibacterial effects of Carica papaya fruit on common wound organisms. West Indian Med J 52(4): 290-292.

24. Yismaw G, Tessema B, Mulu A, Tiruneh M (2008) The in-vitro assessment of antibacterial effect of papaya seed extract against bacterial pathogens isolated from urine, wound and stool. Ethiop Med J 46(1): 71-77.

25. Department of Microbiology and Fermentation Technology, JSBB, SHIATS- Deemed to be University, Naini, UP, India 211008.

26. Peter JK, Kumar Y, Pandey P, Masih H (2014) Antibacterial Activity of Seed and Leaf Extract of Carica Papaya var. Pusa dwarf Linn. IOSR J Pharm Biol Sci 9(2): 29-37.

Assets of Publishing with us
RESEARCHES $\quad \begin{aligned} & \text { Global archiving of articles } \\ & \text { - Immediate, unrestricted online access } \\ & \text { - Rigorous Peer Review Process } \\ & \text { https://biomedres.us/ }\end{aligned}$

